\title{
Comparison of the effects of sevoflurane and propofol on core body temperature during laparoscopic abdominal surgery
}

\author{
Hyun-Jeong Kwak ${ }^{1}$, Sang-Kee $\mathrm{Min}^{2}$, In-Kyong $\mathrm{Yi}^{2}$, Young Jin Chang ${ }^{1}$, and Jong-Yeop Kim² \\ Department of Anesthesiology and Pain Medicine, ${ }^{1}$ Gachon University of Science and Medicine, Gil Medical Center, Incheon, \\ ${ }^{2}$ Ajou University School of Medicine, Suwon, Korea
}

Background: A decrease in core body temperature caused by heat distribution depends on the anesthetic agent used. The purpose of this study is to investigate the effects of sevoflurane and propofol on core temperature during laparoscopic major abdominal surgery requiring pneumoperitoneum of more than $90 \mathrm{~min}$.

Methods: Fifty adult patients undergoing laparoscopic major abdominal surgery were randomly assigned to either a sevoflurane group $(n=25)$ or a propofol group $(n=25)$. In the sevoflurane group, anesthesia was induced with propofol $2 \mathrm{mg} / \mathrm{kg}$, remifentanil $1.0 \mu \mathrm{g} / \mathrm{kg}$, and maintained with $0.8-2.0$ vol\% sevoflurane and $0.1-0.2 \mu \mathrm{g} / \mathrm{kg} / \mathrm{min}$ remifentanil. In the propofol group, anesthesia was induced with the effect-site concentration of propofol of $5.0 \mu \mathrm{g} /$ $\mathrm{ml}$ and remifentanil $4 \mathrm{ng} / \mathrm{ml}$, and maintained with the effect-site concentration of propofol of $2-3.5 \mu \mathrm{g} / \mathrm{ml}$ and remifentanil $3-5 \mathrm{ng} / \mathrm{ml}$. Core body temperature was measured with an esophageal stethoscope with a temperature sensor after the start of the pneumoperitoneum (baseline) and at 15-min intervals until completion of surgery.

Results: During the study period, core temperature was comparable between the two groups. When compared with baseline values, core temperatures in both groups were significantly decreased $45 \mathrm{~min}$ after pneumoperitoneum.

Conclusions: This study demonstrated that in patients undergoing prolonged laparoscopic surgery, a decrease in core body temperature during sevoflurane-remifentanil anesthesia was not different than propofol-remifentanil anesthesia, and the incidence of hypothermia of the two groups did not differ. (Korean J Anesthesiol 2011; 61: 133-137)

Key Words: Hypothermia, Laparoscopy, Propofol, Sevoflurane.

Received: December 17, 2010. Revised: 1st, January 11, 2011; 2nd, January 31, 2011. Accepted: February 7, 2011.

Corresponding author: Jong-Yeop Kim, M.D., Department of Anesthesiology and Pain Medicine, Ajou University School of Medicine, San 5, Wonchon-dong, Yeongtong-gu, Suwon 443-721, Korea. Tel: 82-31-219-5574, Fax: 82-31-219-5579, E-mail: kjyeop@ajou.ac.kr

(c) This is an open-access article distributed under the terms of the Creative Commons Attribution Non-Commercial License (http:// creativecommons.org/licenses/by-nc/3.0/), which permits unrestricted non-commercial use, distribution, and reproduction in any medium, provided the original work is properly cited. 


\section{Introduction}

Hypothermia, defined as a body temperature of $<36^{\circ} \mathrm{C}$, is observed in approximately $60 \%$ of patients undergoing surgery [1]. It can lead to serious complications, including myocardial ischemia [2], impaired coagulation [3], increased incidence of surgical wound infections, and prolonged hospitalization [4]. Despite the absence of environmental exposure of the wound and abdominal viscera, hypothermia has been reported to occur during laparoscopic surgery $[5,6]$. Exposure of the abdominal cavity to large volumes of cold and dry carbon dioxide $\left(\mathrm{CO}_{2}\right)$ insufflation gas has been implicated as a potential source of heat loss during laparoscopy $[5,6]$.

Both sevoflurane and propofol are used for anesthesia during laparoscopic surgery. Previous studies have reported that the decrease in core temperature during general anesthesia depends on the type of anesthetic [7,8]. Ikeda and colleagues [8] demonstrated that core temperatures in patients who received propofol were consistently lower than those in patients who received inhaled sevoflurane. However, other studies have reported that sevoflurane-based anesthesia did not affect cooling and rewarming for deliberate mild hypothermia compared with propofol-based anesthesia [9]. Since there are no data comparing the effects of sevoflurane and propofol on core temperature during prolonged laparoscopic surgery, this study investigated the effects of sevoflurane and propofol on core temperature during laparoscopic major abdominal surgery requiring pneumoperitoneum.

\section{Materials and Methods}

After procedure approval from the institutional review board, adult patients undergoing laparoscopic major abdominal surgery gave informed consent and were studied prospectively. Exclusion criteria included a body mass index of more than 30 $\mathrm{kg} / \mathrm{m}^{2}$, coronary occlusive disease, and respiratory insufficiency. Using a computer generated randomization table, 50 patients, ASA class I or II, were randomly assigned to either sevoflurane group $(n=25)$ or propofol group $(n=25)$ when they arrived in the operating room (OR). Laparoscopic surgeries requiring prolonged pneumoperitoneum time, such as gastrectomy, colectomy, or low anterior resection (LAR) were included in this study. Pneumoperitoneum pressure was maintained at a level of $12-15 \mathrm{mmHg}$. The room temperature was maintained at $22-$ $23^{\circ} \mathrm{C}$ for both groups. An upper body blanket was applied to all patients, and when the core temperature of a patient fell below $35.0^{\circ} \mathrm{C}$, a forced air warmer (Bair Hugger, Augustine Medical Inc, MN, USA) and a warming mattress with circulating water at $38^{\circ} \mathrm{C}$ were applied.

Patients were premedicated with an intramuscular injection of midazolam $2 \mathrm{mg}$ and glycopyrrolate $0.2 \mathrm{mg}$. On arrival in the OR, standard anesthetic monitors were attached and a $20 \mathrm{G}$ catheter was inserted into the radial artery under local anesthesia for continuous monitoring of arterial pressure. To obtain a bispectral index (BIS) score, BIS monitoring (BIS VISTA monitor Revision 3.0, Aspect Medical Systems, Norwood, MA, USA) was applied prior to induction of anesthesia and a fourelectrode sensor (Quatro Sensor ${ }^{\mathrm{TM}}$, Aspect Medical Systems, Newton, MA) was placed on the forehead according to the manufacturer's instructions after alcohol cleaning to reduce skin-electrode impedance. After induction, a urinary catheter was inserted for measurement of hourly urine output.

In the sevoflurane group, anesthesia was induced with propofol $2 \mathrm{mg} / \mathrm{kg}$, remifentanil $1.0 \mu \mathrm{g} / \mathrm{kg}$, and rocuronium 0.6 $\mathrm{mg} / \mathrm{kg}$, and maintained with $0.8-2.0$ vol\% sevoflurane and $0.1-$ $0.2 \mu \mathrm{g} / \mathrm{kg} / \mathrm{min}$ remifentanil. In the propofol group, anesthesia was induced with the effect-site concentration of propofol 5.0 $\mu \mathrm{g} / \mathrm{ml}$ and remifentanil $4 \mathrm{ng} / \mathrm{ml}$, and rocuronium $0.6 \mathrm{mg} / \mathrm{kg}$. A commercially available target controlled infusion (TCI) pump (Orchestra $^{\circledR}$, Fresenius Vial, Brezins, France) was used, and the pharmacokinetic sets used for calculation of target effect-site concentrations for propofol and remifentanil were Schnider and colleagues' model [10] and Minto and colleagues' model [11], respectively. The lungs were ventilated with a tidal volume of $7-10 \mathrm{ml} / \mathrm{kg}$ and a respiratory rate of $8-12$ breaths $/ \mathrm{min}$ in order to maintain an end-tidal carbon dioxide tension $\left(\mathrm{ETCO}_{2}\right)$ of $30-35 \mathrm{mmHg}$ at $60 \%$ inspired oxygen with air. The tidal volume and respiratory rate were reset to maintain an $\mathrm{ETCO}_{2}$ between 35-40 mmHg after pneumoperitoneum in both groups. The anesthetic agents were maintained and adjusted with the effectsite concentration of propofol $2-3.5 \mu \mathrm{g} / \mathrm{ml}$ in the propofol group and sevoflurane $0.8-2.0$ vol\% in the sevoflurane group to obtain BIS values between 40 and 55 . None of the fluids were warmed. Hartmann's solution and 6\% hydroxyethyl starch in normal saline (NS) solution (Voluven ${ }^{\mathrm{TM}}$, Fresenius Kabi, Bad Homberg, Germany) were administered. Hartmann's solution was infused at a constant rate of approximately $6 \mathrm{ml} / \mathrm{kg} / \mathrm{h}$. The maximum dose of $6 \%$ hydroxyethyl starch in NS solution was $50 \mathrm{ml} / \mathrm{kg}$. Packed red blood cells were transfused when hemoglobin fell below $8 \mathrm{~g} / \mathrm{dl}$.

Hemodynamic variables, $\mathrm{ETCO}_{2}$, and temperatures were monitored using Datex-Ohmeda AS/3 modules. Hemodynamic variables were measured at 5-minute intervals using DatexOhmeda S $/ 5^{\mathrm{TM}}$ Collect software (GE Healthcare, Helsinki, Finland) and recorded at $10 \mathrm{~min}$ after the induction of anesthesia (T1), $40 \mathrm{~min}$ after pneumoperitoneum (T2), at the end of surgery (T3), and $1 \mathrm{~h}$ after the surgery (T4). Core body temperature was measured with an esophageal stethoscope with a temperature sensor (DeRoyal Inc., Powell, TN, USA) after the start of pneumoperitoneum (baseline) and at 15-min 
intervals until the completion of surgery. Body temperature was also measured in the postanesthesia care unit (PACU) using a tympanic thermometer (ThermoScan IRT 1020, Braun, Germany). In PACU, a Bair Hugger forced-air warmer was applied to those patients with a tympanic temperature below $36^{\circ} \mathrm{C}$.

Sample size calculation was performed based on a previous study that reported the core body temperature during laparoscopic abdominal surgery with sevoflurane-remifentanil anesthesia [12]: $90 \%$ power to detect a mean difference of $0.4^{\circ} \mathrm{C}$ in core body temperature between sevoflurane and propofol anesthesia during prolonged pneumoperitoneum with a SD of $0.4^{\circ} \mathrm{C}$ and an alpha level of 0.05 using an independent t-test. And, we calculated that 22 patients would be needed in each group. In order to compensate for an estimated dropout rate of $10 \%, 25$ patients for each group were recruited.

SPSS 13.0 (SPSS Inc, Chicago, IL, USA) was used for statistical analyses. All data are expressed as mean \pm SD or number of patients. Data between the groups were compared by use of an independent t-test. Changes between time points within the group were compared using repeated measures of univariate analysis of variance (ANOVA) with post hoc comparisons using

Table 1. Patient Characteristics

\begin{tabular}{lcc}
\hline & $\begin{array}{c}\text { Sevoflurane } \\
(\mathrm{n}=25)\end{array}$ & $\begin{array}{c}\text { Propofol } \\
(\mathrm{n}=25)\end{array}$ \\
\hline Age (yr) & $56.3 \pm 7.9$ & $59.5 \pm 6.9$ \\
Weight (kg) & $61.6 \pm 11.2$ & $64.0 \pm 10.4$ \\
Sex (M/F) & $13 / 12$ & $18 / 7$ \\
Medical history (n) & & \\
$\quad$ Hypertension & 9 & 8 \\
$\quad$ Diabetes mellitus & 4 & 4 \\
Anesthesia time (min) & $222 \pm 67$ & $238 \pm 71$ \\
Pneumoperitoneum time (min) & $131 \pm 45$ & $135 \pm 38$ \\
Time interval (min) & & \\
Fluid balance, & & \\
intraoperative (ml) & & \\
$\quad$ Crystalloid & $29 \pm 7$ & $32 \pm 9$ \\
$\quad$ Colloid & $1,000[800-1,250]$ & $1,300[950-1,750]$ \\
$\quad \begin{array}{l}\text { Urine output, intraoperative } \\
\text { Estimated blood loss }\end{array}$ & $500[400-500]$ & $550[400-775]$ \\
\hline
\end{tabular}

Values indicate mean \pm SD or number of patients or median [interquartile range]. Time interval: time interval from anesthesia induction to the start of pneumoperitoneum. the Dunett's test. A P value $<0.05$ was considered statistically significant.

\section{Results}

No significant differences between the two groups' patient characteristics were observed (Table 1). No surgery was converted to open laparotomy. The hemodynamic parameters are summarized in Table 2. During the study period, the mean arterial pressure and heart rate were comparable between the two groups, except that HR was significantly higher in the sevoflurane group than in the propofol group at $\mathrm{T} 1$. When compared with T1, HR was decreased at T2 and T3 in both groups.

Temperature data from 105 min was not shown because the core temperature of 18 patients from the sevoflurane group and 22 patients from the propofol group fell below $35^{\circ} \mathrm{C}$ and a forced air warmer was applied. Core body temperatures after anesthesia induction were $36.1 \pm 0.5^{\circ} \mathrm{C}$ and $36.0 \pm 0.35^{\circ} \mathrm{C}$ in the sevoflurane and the propofol group, respectively, and there was no statistically significant difference. Changes in body temperature after pneumoperitoneum are illustrated in Fig. 1.

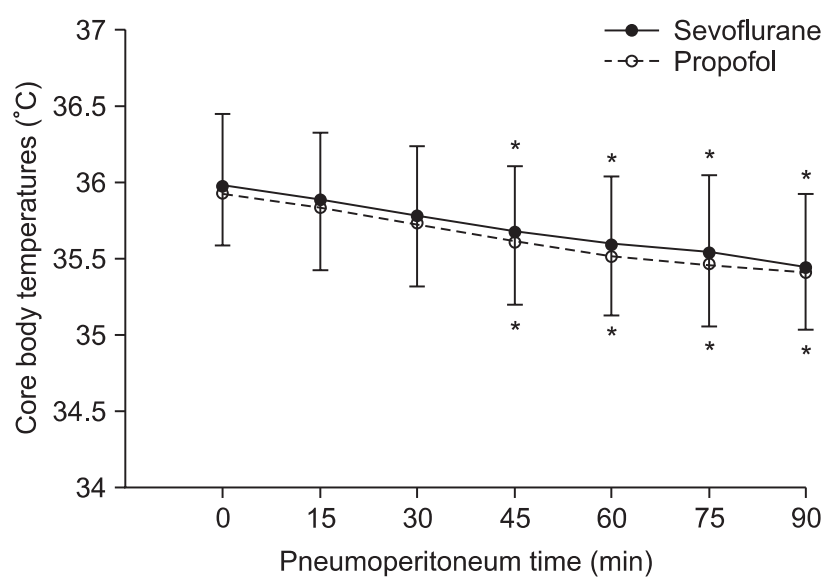

Fig. 1. Changes in core temperature during laparoscopic abdominal surgery. There was no significant difference between the two groups. $* \mathrm{P}<0.05$, vs. baseline values within the group. Baseline (0): after the start of pneumoperitoneum, 15-90: minutes after the insufflation of $\mathrm{CO}_{2}$.

Table 2. Hemodynamic Parameters

\begin{tabular}{lllll}
\hline & & T1 & T2 & T3 \\
\hline MAP (mmHg) & Sevoflurane & $95 \pm 14$ & $90 \pm 14$ & $88 \pm 15$ \\
& Propofol & $98 \pm 13$ & $92 \pm 11$ & $89 \pm 10$ \\
HR (beats/min) & Sevoflurane & $77 \pm 13$ & $60 \pm 10^{\dagger}$ & $63 \pm 13$ \\
& Propofol & $70 \pm 8^{*}$ & $64 \pm 9^{\dagger}$ & $51 \pm 13^{\dagger}$ \\
\end{tabular}

Values indicate mean \pm SD. MAP: mean arterial pressure, HR: heart rate, T1: 10 min after anesthesia induction, T2: 40 min after insufflation of $\mathrm{CO}_{2}$, T3: at the end of surgery, T4: $60 \mathrm{~min}$ after arrival of the post-anesthetic care unit. ${ }^{*} \mathrm{P}<0.05$, vs. sevoflurane group, ${ }^{\dagger} \mathrm{P}<0.05$, vs. baseline values (T1) within the group. 
During the study period, core temperature was comparable between the two groups. When compared with baseline values (after the start of pneumoperitoneum), core temperatures in both groups showed a significant decrease at $45 \mathrm{~min}$ after pneumoperitoneum. Packed red blood cells warmed by an electric warming device were transfused into two patients of the sevoflurane group and one patient of the propofol group 90 min after pneumoperitoneum. Tympanic body temperatures in PACU were $36.0 \pm 0.6^{\circ} \mathrm{C}$ and $35.9 \pm 0.6^{\circ} \mathrm{C}$ in the sevoflurane and the propofol group, respectively, and there was no statistically significant difference.

\section{Discussion}

This study demonstrated that in patients undergoing prolonged laparoscopic surgery, the decrease in core body temperature during administration of sevoflurane-remifentanil anesthesia did not differ in comparison with propofol-remifentanil anesthesia, and the incidence of hypothermia did not differ between the groups.

Hypothermia after induction of general anesthesia develops with a characteristic pattern consisting of three distinct phases [13-15]: 1) an initial rapid decrease in core temperature that results from core-to-peripheral redistribution of body heat; 2) a slower, linear decrease in core temperature caused by heat loss exceeding metabolic heat production; and 3) a core temperature plateau resulting from decreased cutaneous heat loss and constraint of metabolic heat to the core thermal compartment upon development of thermoregulatory vasoconstriction. The assumption of this study was that the type of anesthetic might affect the redistribution of body heat and cutaneous heat loss, as well as inhibition of thermoregulatory vasoconstriction during pneumoperitoneum with cold and dry $\mathrm{CO}_{2}$, so that the decrease of core temperature may differ according to the anesthetic agent chosen.

The effects of sevoflurane and propofol on core body temperature during general anesthesia have been studied; however, their results remain controversial $[8,9,16]$. Previous studies have reported that core temperatures in patients who receive IV propofol for anesthetic induction were consistently lower than those in patients who received inhaled sevoflurane for anesthetic induction during minor oral surgery [8]. Meanwhile, Im and colleagues [16] demonstrated that the decrease in core body temperature during sevoflurane-remifentanil anesthesia did not differ compared with that of propofol-remifentanil anesthesia in female patients undergoing open hysterectomy. As in their report [16], we found no difference in the two groups' change in core temperature during laparoscopic surgery.

Laparoscopic surgery has an anticipated advantage, which could decrease the incidence of hypothermia, because heat loss from exposed abdominal contents is not a factor. However, our study has shown that during prolonged laparoscopic surgery without precautionary warming methods, core body temperature decreased significantly from 45 min after pneumoperitoneum regardless of the type of anesthetics. In addition, Berber and colleagues [17] demonstrated that patients who undergo laparoscopic and open procedures of similar duration under endotracheal general anesthesia have similar profiles in terms of perioperative hypothermia.

In humans, the heat capacity of the body is $0.812 \mathrm{Cal} / \mathrm{kg}{ }^{\circ} \mathrm{C}$ [18]. This means that to lower the body temperature of a $60 \mathrm{~kg}$ human by $1^{\circ} \mathrm{C}, 49 \mathrm{Cal}$ should be lost. A previous study of heat loss during laparoscopy suggested that, assuming a theoretical worst-case of complete water saturation and heating of cold, dry inflow gas up to a flow rate of $7 \mathrm{~L} / \mathrm{min}$, the total heat loss would be $0.027 \mathrm{Cal} / \mathrm{L}$ [18]. In this study, the mean duration of gas insufflation was $130 \mathrm{~min}$, the mean gas leak totaled $903 \mathrm{~L}$, and the mean weight of patients was $63 \mathrm{~kg}$. Thus, assuming a worst hypothetical case of complete water saturation of dry insufflated gas in this study, a $63 \mathrm{~kg}$ patient undergoing 130 min of pneumoperitoneum with a continuous $(7 \mathrm{~L} / \mathrm{min})$ gas leak totaling $910 \mathrm{~L}$ would, at worst, lose enough heat to lower the body temperature by $0.48^{\circ} \mathrm{C}$. Meanwhile, a previous study of core temperature changes in healthy volunteers undergoing general anesthesia alone demonstrated that core temperature decreased $1.6 \pm 0.3^{\circ} \mathrm{C}$ in the first hour of anesthesia, and, during the subsequent $2 \mathrm{~h}$, an additional $1.1 \pm 0.3^{\circ} \mathrm{C}$ [14]. Therefore, core-to-peripheral redistribution of body heat due to general anesthesia might be a major contributor to the decrease of body temperature in this study.

Peripheral vasoconstriction plays a major role in the thermoregulatory response to reduced body temperature. Therefore, non-thermal factors affecting the cardiovascular system might modulate thermoregulatory control. Relative preservation of thermoregulatory vasoconstriction has been reported to be associated with activation of the sympathetic nervous system [19]. Furthermore, $\mathrm{CO}_{2}$ pneumoperitoneum could induce an increase in sympathetic activity, which may result from increased intra-abdominal pressure, hypercarbia, or an increased plasma concentration of catecholamine [20]. In addition, since Sato and colleagues [20] demonstrated that the choice of general anesthetic did not appear to have a major influence on change in the cardiac autonomic nervous system after induction of pneumoperitoneum, the two anesthetic regimens in this study might have similar thermoregulatory vasomotor effects during pneumoperitoneum.

Ikeda and colleagues [8] suggested that even a very brief period of vasodilation during anesthetic induction causes substantial redistribution hypothermia. However, because some patients are reluctant to allow themselves to undergo the 
inhalational induction with sevoflurane, this technique was not used in the current study, although this technique might decrease the change in core temperature after anesthesia induction. However, after the same method of induction with IV propofol, the effects of sevoflurane and propofol on cooling and rewarming during deliberate mild hypothermia have been reported not to differ [9]. In addition, in this study, one of the limitations was that the post hoc power was low. Advocates of post hoc power recommend its use especially when a statistically nonsignificant result is obtained. The thinking here is that such a lack of significance could be due either to low power or to a truly small effect; if the post hoc power is found to be high, then the argument is made that the nonsignificance must then be due to a small effect size. In this study, we obtained a post hoc power of about $52.8 \%$ from core temperature data at $45 \mathrm{~min}$ after pneumoperitoneum. However, there are some problems with the use of post hoc power analyses. When a clinical trial leads to a negative result, the calculation of power based on the observed results will always lead to a low value [21]. Because of the significant limitations of a post hoc power analysis, many experts advise against calculating power after study completion [21-23]. It might be worth trying different anesthetic induction agents in future studies.

In conclusion, this study demonstrated that after the same method of induction with IV propofol, sevoflurane and propofol cause similar changes in core temperature in patients undergoing laparoscopic surgery under general anesthesia. This study has shown that intraoperative hypothermia after laparoscopy developed frequently regardless of the type of anesthetic. Therefore, preventive measures for hypothermia should be considered in patients undergoing laparoscopic major abdominal surgery.

\section{References}

1. Frank SM, Shir Y, Raja SN, Fleisher LA, Beattie C. Core hypothermia and skin-surface temperature gradients: epidural versus general anesthesia and the effects of age. Anesthesiology 1994; 80: 502-8.

2. Frank SM, Beattie C, Christopherson R, Norris EJ, Perler BA, Williams GM, et al. Unintentional hypothermia is associated with postoperative myocardial ischemia. Anesthesiology 1993; 78: 468-76.

3. Valeri CR, Feingold H, Cassidy G, Ragno G, Khuri S, Altschule MD. Hypothermia-induced reversible platelet dysfunction. Ann Surg 1987; 205: 175-81.

4. Kurz A, Sessler DI, Lenhardt R. Perioperative normothermia to reduce the incidence of surgical-wound infection and shorten hospitalization. Study of wound infection and temperature group. N Engl J Med 1996; 334: 1209-15.

5. Nguyen NT, Fleming NW, Singh A, Lee SJ, Goldman CD, Wolfe BM. Evaluation of core temperature during laparoscopic and open gastric bypass. Obes Surg 2001; 11: 570-5.

6. Bessell JR, Karatassas A, Patterson JR, Jamieson GG, Maddern GJ.
Hypothermia induced by laparoscopic insufflation. A randomized study in a pig model. Surg Endosc 1995; 9: 791-6.

7. Ikeda T, Kazama T, Sessler DI, Toriyama S, Niwa K, Shimada C, et al. Induction of anesthesia with ketamine reduces the magnitude of redistribution hypothermia. Anesth Analg 2001; 93: 934-8.

8. Ikeda T, Sessler DI, Kikura M, Kazama T, Ikeda K, Sato S. Less core hypothermia when anesthesia is induced with inhaled sevoflurane than with intravenous propofol. Anesth Analg 1999; 88: 921-4.

9. Iwata T, Inoue S, Kawaguchi M, Takahashi M, Sakamoto T, Kitaguchi $\mathrm{K}$, et al. Comparison of the effects of sevoflurane and propofol on cooling and rewarming during deliberate mild hypothermia for neurosurgery. Br J Anaesth 2003; 90: 32-8.

10. Schnider TW, Minto CF, Gambus PL, Andresen C, Goodale DB, Shafer SL, et al. The influence of method of administration and covariates on the pharmacokinetics of propofol in adult volunteers. Anesthesiology 1998; 88: 1170-82.

11. Minto CF, Schnider TW, Egan TD, Youngs E, Lemmens HJ, Gambus PL, et al. Influence of age and gender on the pharmacokinetics and pharmacodynamics of remifentanil. I. Model development. Anesthesiology 1997; 86: 10-23.

12. Kwak HJ, Jo YY, Lee KC, Kim YB, Shinn HK, Kim JY. Acid-base alterations during laparoscopic abdominal surgery: a comparison with laparotomy. Br J Anaesth 2010; 105: 442-7.

13. Sessler DI, McGuire J, Moayeri A, Hynson J. Isoflurane-induced vasodilation minimally increases cutaneous heat loss. Anesthesiology 1991; 74: 226-32.

14. Matsukawa T, Sessler DI, Sessler AM, Schroeder M, Ozaki M, Kurz A, et al. Heat flow and distribution during induction of general anesthesia. Anesthesiology 1995; 82: 662-73.

15. Hynson JM, Sessler DI. Intraoperative warming therapies: a comparison of three devices. J Clin Anesth 1992; 4: 194-9.

16. Im UJ, Lee DJ, Kim MC, Lee JS, Lee SJ. Difference in core temperature in response to propofol-remifentanil anesthesia and sevofluraneremifentanil anesthesia. Korean J Anesthesiol 2009; 57: 704-8.

17. Berber E, String A, Garland A, Engle KL, Kim KM, Ituarte P, et al. Intraoperative thermal regulation in patients undergoing laparoscopic vs open surgical procedures. Surg Endosc 2001; 15: 281-5.

18. Huntington TR, LeMaster CB. Laparoscopic hypothermia: heat loss from insufflation gas flow. Surg Laparosc Endosc 1997; 7: 153-5.

19. Nakajima Y, Mizobe T, Takamata A, Tanaka Y. Baroreflex modulation of peripheral vasoconstriction during progressive hypothermia in anesthetized humans. Am J Physiol Regul Integr Comp Physiol 2000; 279: R1430-6.

20. Sato N, Kawamoto M, Yuge O, Suyama H, Sanuki M, Matsumoto $\mathrm{C}$, et al. Effects of pneumoperitoneum on cardiac autonomic nervous activity evaluated by heart rate variability analysis during sevoflurane, isoflurane, or propofol anesthesia. Surg Endosc 2000; 14: 362-6.

21. Goodman SN, Berlin JA. The use of predicted confidence intervals when planning experiments and the misuse of power when interpreting results. Ann Int Med 1994; 121: 200-6.

22. Zumbo BD, Hubley AM. A note on misconceptions concerning prospective and retrospective power. Statistician 1998; 47: 385-8.

23. Levine M, Ensom MH. Post hoc power analysis: an idea whose time has passed? Pharmacotherapy 2001; 21: 405-9. 